\title{
A low-dose mindfulness intervention and recovery from work: Effects on psychological detachment, sleep quality, and sleep duration
}

Citation for published version (APA):

Hulsheger, U. R., Feinholdt, A., \& Nubold, A. (2015). A low-dose mindfulness intervention and recovery from work: Effects on psychological detachment, sleep quality, and sleep duration. Journal of Occupational and Organizational Psychology, 88(3), 464-489. https://doi.org/10.1111/joop.12115

Document status and date:

Published: 01/09/2015

DOI:

10.1111/joop. 12115

Document Version:

Publisher's PDF, also known as Version of record

Document license:

Taverne

Please check the document version of this publication:

- A submitted manuscript is the version of the article upon submission and before peer-review. There can be important differences between the submitted version and the official published version of record.

People interested in the research are advised to contact the author for the final version of the publication, or visit the DOI to the publisher's website.

- The final author version and the galley proof are versions of the publication after peer review.

- The final published version features the final layout of the paper including the volume, issue and page numbers.

Link to publication

\footnotetext{
General rights rights.

- You may freely distribute the URL identifying the publication in the public portal. please follow below link for the End User Agreement:

www.umlib.nl/taverne-license

Take down policy

If you believe that this document breaches copyright please contact us at:

repository@maastrichtuniversity.nl

providing details and we will investigate your claim.
}

Copyright and moral rights for the publications made accessible in the public portal are retained by the authors and/or other copyright owners and it is a condition of accessing publications that users recognise and abide by the legal requirements associated with these

- Users may download and print one copy of any publication from the public portal for the purpose of private study or research.

- You may not further distribute the material or use it for any profit-making activity or commercial gain

If the publication is distributed under the terms of Article $25 \mathrm{fa}$ of the Dutch Copyright Act, indicated by the "Taverne" license above, 


\title{
A low-dose mindfulness intervention and recovery from work: Effects on psychological detachment, sleep quality, and sleep duration
}

\author{
Ute R. Hülsheger '*, Alina Feinholdt ${ }^{2}$ and Annika Nübold' \\ 'Maastricht University, The Netherlands \\ ${ }^{2}$ University of Amsterdam, The Netherlands
}

\begin{abstract}
Although playing a crucial role for the prevention of long-term health impairment, interventions aiming at the improvement of employees' recovery processes are still scarce. In this study, we therefore investigated the effectiveness of a low-dose mindfulness intervention for recovery from work. In addition, differential responding to the treatment in terms of treatment-by-baseline interactions was studied. A sample of 140 employees participated in a randomized field experiment with a self-training and a wait-list control group. Three central recovery processes (psychological detachment, sleep quality, and sleep duration) were assessed with event-sampling methodology involving daily measurements over 10 workdays. Growth curve analyses revealed intervention effects on sleep quality and sleep duration. No effects were found for psychological detachment after work and for the proposed treatment-by-baseline interactions. Our findings are discussed in the context of occupational health promotion in general and mindfulnessbased interventions in specific.
\end{abstract}

\section{Practitioner points}

- Although daily recovery from the demands of work has been shown to be vital for employee well-being and performance, research on how workplace interventions can help improve recovery is still scarce.

- This study investigated the effectiveness of a brief, economic mindfulness intervention on processes that are vital for recovery - psychological detachment, sleep quality, and sleep duration.

- Findings revealed positive effects of the intervention on sleep quality and duration, but not on psychological detachment.

Resource-oriented interventions at work try to enhance well-being and performance in the workplace by targeting a variety of employees' personal, social, and job-related resources (e.g., Bond, Flaxman, \& Bunce, 2008; Luthans, Avey, \& Patera, 2008; Ouweneel, Le Blanc, \& Schaufeli, 2013). Although these positive psychological interventions have great potential for occupational health promotion, more is to be learned about the resources that qualify for optimal improvement, the dynamics of participants' progress during these interventions as well as the specific boundary conditions that restrict or boost programme effectiveness (Lyubomirsky \& Layous, 2013). Thus, questions on what

*Correspondence should be addressed to Ute R. Hülsheger, P.O. Box 616, 6200 MD Maastricht, The Netherlands (email: ute. hulsheger@maastrichtuniversity.nl). 
to train, how (long) to train, and whom to train in order to get the most out of often costly and time-consuming interventions, need to be addressed.

With this study, we aim to contribute to this line of research by testing the effects of a low-dose self-training mindfulness intervention on recovery processes. Mindfulness describes a state of consciousness characterized by a non-judgmental and attentive state of awareness of momentary events and experiences (Bishop et al., 2004; Brown, Ryan, \& Creswell, 2007). Initial evidence on the benefits of mindfulness in the context of work stems from studies that have investigated the role of natural variations in mindfulness (mostly trait mindfulness) and their relations to work-related outcomes, such as work-life balance, job satisfaction, well-being, performance, and recovery (Allen \& Kiburz, 2012; Dane \& Brummel, 2014; Hülsheger, Alberts, Feinholdt, \& Lang, 2013; Hülsheger et al., 2014; Reb, Narayanan, \& Ho, 2015). In addition to these cross-sectional and diary studies on mindfulness in the work context, there is a different line of research investigating the effectiveness of mindfulness interventions for working adults. The majority of these studies tested the effectiveness of comprehensive mindfulness interventions, typically the Mindfulness-Based Stress Reduction programme (MBSR; Kabat-Zinn, 1982, 1990), and typically for health care professionals (e.g., Cohen-Katz et al., 2005). Recently, researchers have started to adapt the MBSR to the demands of the working population (e.g., Michel, Bosch, \& Rexroth, 2014; Wolever et al., 2012). With this study, we aim to build upon and extend this line of work.

First, we study the effectiveness of an economic, low-dose mindfulness intervention developed by Hülsheger et al. (2013) that incorporates core elements of MBSR and is customized to the needs of working adults. In contrast to the mindfulness interventions discussed above, the intervention is self-administered; it only spans a period of 2 weeks (in contrast to typically 8 weeks in MBSR) and involves relatively brief daily mindfulness practices. Research in the field of positive psychology has shown that already small-scale interventions, such as reflecting on blessings (Emmons \& McCullough, 2003) or performing kind acts (Lyubomirsky, Sheldon, \& Schkade, 2005) each day, may help to enhance individuals' personal resources and their well-being.

Second, in studying the effectiveness of this low-dose mindfulness intervention, we focus on employees' daily recovery processes as outcome variables. Specifically, we test the effects of the intervention on individuals' psychological detachment from work during non-work time as well as subsequent sleep quality and quantity. Although research in the field of occupational health psychology has emphasized the importance of successful daily recovery from the demands of work (Fritz, Yankelevich, Zarubin, \& Barger, 2010; Sonnentag, Binnewies, \& Mojza, 2008; Sonnentag, Mojza, Demerouti, \& Bakker, 2012; Sonnentag \& Zijlstra, 2006), research on how employees' recovery processes can be facilitated through training is still scarce (for an exception see Hahn, Binnewies, Sonnentag, \& Mojza, 2011). As previous research has indicated that state mindfulness is positively related to successful recovery (Hülsheger et al., 2014), a mindfulness intervention may prove especially useful to foster recovery.

Third, scholars have called for research that not only focuses on whether mindfulness interventions are effective, but also specifies for whom they are most effective (e.g., Roth \& Fonagy, 2005; Shapiro, Brown, Thoresen, \& Plante, 2011). Knowledge on these contingencies may be an important means for organizations to streamline health programmes, tailor them to specific groups, and spare resources. We therefore investigate treatment-by-baseline interactions - systematic differences in the benefit obtained by individuals with different baseline levels as a result of an intervention (Khoo, 2001). 
Fourth, with this study we combine a randomized field trial with event-sampling methodology (Hülsheger et al., 2013). This set-up bears a number of advantages over typical set-ups involving only pre- and post-intervention measurements in that it provides valuable insights on how outcome variables change over time during the intervention and allows comparing these change trajectories between the intervention and control group.

\section{Mindfulness and mindfulness interventions}

Mindfulness is the English translation of the Pali word 'sati' which connotes 'lucid awareness'. According to Kabat-Zinn (2003), mindfulness is defined as an 'awareness that emerges through paying attention on purpose in the present moment, non-judgmentally to the unfolding of experience moment by moment' (p. 145). Cultivating present-moment attention and awareness allows the practitioner to attain the role of an external agent who observes the constant flow of thoughts, sensations, and emotions and how these are transformed into entities of personal meaning (Williams, 2010). Both awareness and attention allow the practitioner to understand that neither thoughts nor emotions are eternal but subject to change (Dreyfus, 2011). This way of looking at things allows the practitioner to separate what is really experienced in any moment and what is simply the result of internally generated interpretations (Kabat-Zinn, 2003). Consequentially, mindfulness enables to slow down automatic tendencies and, meanwhile, mitigate emotional reactivity (Dreyfus, 2011).

Since the introduction of the MBSR programme (Kabat-Zinn, 1982, 1990), many different types of mindfulness-based interventions have emerged. While they differ in aspects such as the incorporated meditation practices, treatment duration, or target group, each of them aims at cultivating an open-hearted attention towards externally and internally generated experiences and the way people relate to them (Kabat-Zinn, 2003; Baer, 2003). Both, the variety of interventions and the continuously growing popularity of mindfulness is largely due to its effectiveness as a treatment for numerous somatic and psychological disorders, including anxiety and depression, insomnia, or pain (e.g., Hofmann, Sawyer, Witt, \& Oh, 2010; Ong, Shapiro, \& Manber, 2008; Rosenzweig et al., 2010).

Recently, scholars in the field of work and organizational psychology became increasingly interested in the value of mindfulness in the context of work. Initial evidence on the benefits of mindfulness interventions for employees stems from studies investigating traditional mindfulness interventions with samples from the health care professions and focusing on psychological distress and burnout as outcome variables (e.g., Cohen-Katz et al., 2005; Galantino, Baime, Maguire, Szapary, \& Farrar, 2005; Irving, Dobkin, \& Park, 2009; Krasner et al., 2009). Importantly, traditional mindfulness-based interventions are comprehensive in terms of time investment. For instance, the typical duration of the MBSR programme spans over 8 weeks during which participants attend weekly group meetings for 2 hours or more. Next to this, participants are supposed to devote $45 \mathrm{~min}$ to daily meditation practice. However, time commitment is one of the biggest challenges to the feasibility of mindfulness in everyday life (Sears, Kraus, Carlough, \& Treat, 2011), especially for individuals with busy work schedules and high workload.

Therefore, recent attempts have been made to adapt mindfulness interventions to better fit the requirements of the working population (Klatt, Buckworth, \& Malarkey, 2009; Malarkey, Jarjoura, \& Klatt, 2013; Van Berkel, Boot, Proper, Bongers, \& 
van der Beek, 2013; Wolever et al., 2012). In an endeavour to reduce the time commitment for participants and help them fit mindfulness practices into their busy work lives, weekly group meetings have been shortened, for instance, to $1 \mathrm{hr}$ and daily mindfulness practices have been reduced to 5-15 min (Wolever et al., 2012). Furthermore, daily mindfulness practices that were initially designed for clinical applications and targeted pain and other psychological symptoms were adapted to better fit work-related issues, such as work stress, work-life balance, and self-care (e.g., Michel et al., 2014; Wolever et al., 2012). The condensed intervention used in this study spans two workweeks and involves brief mindfulness practices (about $10 \mathrm{~min}$ ) that can readily be integrated into participants' (work) life (Hülsheger et al., 2013). A unique feature is that it is a pure self-training intervention and does not involve formal group meetings, retreats or contacts with a mindfulness trainer or coach (common elements in traditional mindfulness-based interventions). It is therefore time- and cost-effective both for employees and for organizations. While positive effects of this intervention have already been documented for job satisfaction and emotional exhaustion in a sample of service workers (Hülsheger et al., 2013), it remains to be tested whether it also benefits daily recovery processes in terms of psychological detachment, sleep quality, and sleep duration.

\section{Recovery from work}

The concept of recovery is crucial in understanding under what conditions the exposure to work demands and work stressors leads to long-term health impairments (Geurts \& Sonnentag, 2006). According to the effort-recovery model (Meijman \& Mulder, 1998), effort expenditure at work is associated with acute load reactions, as evidenced, for instance, by an elevated heart rate and the experience of fatigue. These acute load reactions become gradually chronic and impair employee health and well-being in the long run when employees are continuously exposed to workload and when recovery is incomplete (Geurts \& Sonnentag, 2006). Psychological and physiological unwinding from the demands of work during non-work time are thus vitally important, not only to maintain employee well-being and health (e.g., Fritz et al., 2010; Sonnentag, 2001; Sonnentag \& Zijlstra, 2006) but also to facilitate work engagement (Sonnentag et al., 2012), proactivity, and work performance (Binnewies, Sonnentag, \& Mojza, 2009; Fritz et al., 2010). While research on factors that help or hinder recovery from work has grown exponentially in recent years, comparatively little attention has been devoted to develop interventions that foster recovery processes (for an exception see Hahn et al., 2011). This is surprising as these interventions would be of great importance for organizations that seek to maintain a healthy, engaged, and productive workforce.

In examining the effects of the self-training intervention on recovery, we focus on three key aspects, namely psychological detachment from work, sleep quality, and sleep duration (Fritz et al., 2010; Pereira, Meier, \& Elfering, 2013; Querstret \& Cropley, 2012; Sonnentag et al., 2012). Psychological detachment has been defined as an 'individual's sense of being away from the work situation' (Etzion, Eden, \& Lapidot, 1998, p. 579). It does not only involve a physical distance from work and the work situation, but also an abstinence of any work-related feelings or thoughts (Sonnentag \& Fritz, 2007). Accordingly, psychological detachment has been described to be a core recovery experience (Sonnentag \& Fritz, 2015). It has been shown to be related to a range of other important health-, well-being-, and performance-related outcomes, including emotional 
exhaustion, work-family conflict, and work engagement (Demsky, Ellis, \& Fritz, 2014; Fritz \& Sonnentag, 2009; Fritz et al., 2010; Sonnentag, Binnewies, \& Mojza, 2010). ${ }^{1}$

Also sleep plays a key role in recovery processes (Querstret \& Cropley, 2012; Sonnentag et al., 2008). It is the antipode to working, represents total disengagement from work-related activities and (conscious) thoughts, and is thereby not only relevant for psychological unwinding, but also for physical and physiological recovery.

Although recovery research has typically focused on sleep quality (Querstret \& Cropley, 2012; Sonnentag et al., 2008), sleep duration is also an important aspect to consider. While sleep quality is a subjective evaluation of how well an individual slept (Buysse, Reynolds, Monk, Berman, \& Kupfer, 1989), sleep duration captures the total amount of hours a person has slept (which may differ from the time that person has been lying in bed). Although related, sleep quality and sleep duration are theoretically and empirically distinct from one another (Barclay, Eley, Buysse, Tijsdijk, \& Gregory, 2010; Buysse et al., 1989). In recent years, researchers in the field of work and organizational psychology have started paying increasing attention to sleep duration as it has been shown to not only be affected by work (Barnes, Wagner, \& Ghumman, 2012) but also to relate to work-relevant outcomes, such as job satisfaction and organizational citizenship behaviour (Barnes, Ghumman, \& Scott, 2013; Barnes et al., 2012).

Notably, a recent study investigating the effects of a mindfulness-based intervention on work-family balance documented increases in psychological detachment after a 3-week mindfulness intervention (Michel et al., 2014). This study aims to replicate these findings regarding psychological detachment using a different and shorter self-training intervention. Furthermore, our study extends their work by studying sleep quality and duration as outcome variables and by tracking daily intervention-related changes over time by combining an experimental set-up with a diary design.

\section{Effects of mindfulness practices on psychological detachment, sleep quality, and sleep quantity}

Theoretical and empirical work on mindfulness suggests that mindfulness-based practices improve self-regulation of psychological, behavioural, and physiological reactions (Brown et al., 2007; Glomb, Duffy, Bono, \& Yang, 2011; Shapiro, Carlson, Astin, \& Freedman, 2006). It is through these self-regulatory processes that a mindfulness intervention may facilitate successful unwinding from the demands of work and promote recovery in terms of psychological detachment, sleep quality, and sleep duration. Glomb et al. (2011) summarized primary and secondary mechanisms explaining how mindfulness-based practices facilitate self-regulation. In the context of recovery, two central primary mechanisms that facilitate self-regulation are the decoupling of the self from experiences and interoceptive awareness.

\footnotetext{
${ }^{1}$ Rather than including all four recovery experiences defined by Sonnentag and Fritz (2007; psychological detachment, relaxation, mastery experiences, and control), we chose to focus on psychological detachment exclusively: Psychological detachment has been shown to be the recovery experience with the strongest relationship with other important psychological health outcomes, such as emotional exhaustion, health complaints, or depressive symptoms (Sonnentag \& Fritz, 2007), and it has therefore been playing a central role in the recovery literature (Pereira \& Elfering, 2014; Sonnentag, Arbeus, Mahn, \& Fritz, 20l4). Furthermore, theoretical work on mindfulness suggests that mindfulness should have strongest effects on psychological detachment, while relations with the other three recovery experiences are less obvious. Accordingly, previous research has revealed significant relationships between self-reported mindfulness and psychological detachment (Hülsheger et al., 20 I 4), while relationships with relaxation, mastery experience, and control have been shown to be non-existent or small (Marzuq \& Drach-Zahavy, 20I2).
} 
Decoupling of the self from experiences (also referred to as reperceiving or cognitive decentering) has been described as the cornerstone of mindfulness practice (Shapiro et al., 2006). It describes a shift in perspective on what individuals experience: 'Rather than being immersed in the drama of our personal narrative or life story, we are able to stand back and simply witness it' (Shapiro et al., 2006, p. 377). Mindfulness practices promote reperceiving as participants learn to focus on presentmoment experiences and to simply notice external as well as internal events (thoughts, sensations, and emotions) in a non-judgmental way. The goal of mindfulness practices is to strengthen the ability to observe what we are experiencing rather than being completely embedded in it (Shapiro et al., 2006). This, in turn, creates meta-awareness, the ability to be aware of the things dominating the mind at any present moment (Shapiro et al., 2006). Together these qualities facilitate a more objective assessment of external and internal events whereby radical emotional or behavioural reactions to these events can be mitigated. In fact, mindfulness has been shown to enhance adaptive forms of emotion regulation (Arch \& Craske, 2006; Erisman \& Roemer, 2010; Glomb et al., 2011; Hülsheger et al., 2013) and decrease rumination (Glomb et al., 2011; Jain et al., 2007; Shapiro, Brown, \& Biegel, 2007). As employees frequently experience negative events or stress at work, the ability to stand back and simply notice what is with a non-evaluative attitude will help them to keep their emotions on an even keel. It makes them less likely to get caught up in perseverative cognitions regarding the causes and potential implications of these negative events. This will preserve mental resources during work and help them to be less inclined to ruminate, thus helping them to psychologically detach from work during non-work time. Links with sleep quality and duration are twofold: First, reduced rumination will facilitate falling asleep and promote sleep quality (Querstret \& Cropley, 2012). Second, difficulties with falling asleep are often preceded by rigid and controlling attempts to enforce sleep. However, as sleep is not under full voluntary control, trying to enforce sleep has paradoxical effects as it increases presleep cognitive activity, arousal, and anxiety which are incompatible with sleep (Broomfield \& Espie, 2003; Ong, Cardé, Gross, \& Manber, 2011). Reperceiving, the ability to step back and observe, promotes a non-striving attitude and acceptance that one may not fall asleep immediately. It helps to let go of the idea that one has to fall asleep, and it reduces cognitive activity, arousal, and anxiety which helps that sleep comes naturally (Ong et al., 2008).

Apart from decoupling the self from experiences, another mechanism through which mindfulness may benefit recovery processes is through strengthening an individual's interoceptive awareness. Interoceptive awareness refers to individuals' sensitivity to stimuli that originate inside the body (visceral sensations associated with, e.g., respiration, digestion, circulation, or proprioception) and that are involved in maintaining homoeostasis (Craig, 2003). As mindfulness meditation practice involves sustained attention to bodily sensations, such as respiratory sensations and feelings of tension, pain, or physiological arousal, mindfulness has been argued to promote interoceptive awareness (Glomb et al., 2011; Hölzel et al., 2008; Kerr, Sacchet, Lazar, Moore, \& Jones, 2013; Kristeller, Wolever, \& Sheets, 2013). Indeed, neuropsychological research confirmed that mindfulness practice was associated with increased grey matter concentration in brain areas associated with interoceptive awareness (Hölzel et al., 2008). Interoceptive awareness, in turn, may influence self-regulation of behaviour as visceral sensory impulses that reach awareness are likely to affect behaviour, thought, and emotion (Cameron, 2001). This argument is supported by research showing that interoception is 
associated with adaptive self-regulation in general and emotion regulation in particular (Füstös, Gramann, Herbert, \& Pollatos, 2013; Van 't Wout, Faught, \& Menino, 2013). For instance, interoceptive awareness has been shown to be negatively related to obsessive compulsive drinking behaviour (Schmidt, Eulenbruch, Langer, \& Banger, 2013) and positively with the ability to respond adaptively to unfair treatment by others (Van 't Wout et al., 2013).

A heightened awareness of bodily sensations may thus foster recovery. Employees who are aware of early symptoms of stress, exhaustion, or fatigue are more likely to adapt their behaviour and engage in activities that facilitate rather than impede recovery compared with employees who are unaware of their bodily sensations. They may, for instance, avoid stressful work situations and overtime hours, deliberately take a break from work, and engage in leisure activities that have been shown to promote recovery (e.g., physical and social activities; Sonnentag \& Zijlstra, 2006). In doing so, psychological detachment and, in turn, sleep quality may be facilitated. Similarly, becoming aware of the physiological signals of tiredness, employees may go to bed earlier, leading to longer sleep duration.

Taken together, we therefore expect that psychological detachment, sleep quality, and sleep duration increase as a result of the self-administered low-dose mindfulness intervention.

Hypothesis 1: There will be an interaction between time and condition in predicting (a) psychological detachment, (b) sleep quality, and (c) sleep duration. Specifically, (a) psychological detachment, (b) sleep quality, and (c) sleep duration will increase over time in the intervention group, while remaining stable in the control group.

\section{Treatment-by-baseline effects}

Mindfulness researchers have argued that studies into the effectiveness of mindfulness interventions not only need to investigate whether mindfulness interventions are effective, but also for whom they are most effective (Shapiro et al., 2011). Learning more about differential effects of workplace health promotion programmes in general is vital in order to tailor interventions to employees' needs and invest time and money effectively. In investigating differential effects, we will focus on treatment-by-baseline interactions.

Intervention research has frequently documented situations in which individuals with high versus low baseline levels show differential reactions to interventions (Khoo, 2001; MacKinnon, Fairchild, \& Fritz, 2007). Typically, clinical interventions as well as interventions in the field of work and organizational psychology (e.g., Eden \& Aviram, 1993; Eden \& Kinnar, 1991) have had stronger effects for individuals who are more at risk and display low levels of initial functioning. The underlying idea is that those with low baseline levels may have more to gain from an intervention, while ceiling effects may hamper the benefits for those with high baseline levels (Shapiro et al., 2011). For mindfulness-based interventions, findings have been mixed: Jacobs et al. (2011) did find a treatment-by-baseline interaction when investigating the effectiveness of meditation training among healthy participants - those who displayed poorer psychological functioning at baseline benefitted more from the intervention than their higher functioning counterparts. In contrast, Wolitzky-Taylor, Arch, Rosenfield, and Craske (2012) found no interaction effect. Notably however, they examined the effectiveness of 
acceptance and commitment therapy (ACT), which includes not only elements of mindfulness, but also of cognitive behavioural therapy. Thus, the dependence of the effectiveness of mindfulness interventions on participants' baseline levels may differ according to the components of the intervention and the outcome variables that are taken into account. In sum, theoretical arguments and the empirical literature suggest that benefits from mindfulness interventions may differ depending on participants' baseline levels on outcome variables.

Hypothesis 2: There will be an interaction between condition (intervention vs. control group) and baseline levels for (a) psychological detachment, (b) sleep quality, and (c) sleep duration such that gains in recovery processes due to the intervention are stronger for participants with low baseline levels.

\section{The present study}

To investigate the ideas developed above, we used a randomized field experiment in combination with experience sampling methodology (ESM), a set-up previously employed by Hülsheger et al. (2013). Specifically, participants were randomly assigned to the intervention group or a wait-list control group. Both groups participated in a diary study spanning 10 workdays and involving three daily measurement occasions (in the morning, at the end of work, and at bedtime). This set-up bears a number of advantages and allows for a comprehensive evaluation of the self-training intervention, both in terms of outcomes and processes involved. Typically, studies investigating positive psychology interventions in the context of work use randomized pre-test post-test control group designs, involving pre- and post-intervention measurements, and sometimes a follow-up measurement (for an overview see Meyers, van Woerkom, \& Bakker, 2013). Although such a set-up is valuable as it allows making causal inferences and excluding a number of threats to external and internal validity (Cook \& Campbell, 1979), extending this set-up by including daily measurement occasions over two workweeks bears important advantages: First, in the context of recovery, where outcome variables have been shown to be dynamic and to fluctuate from day to day within persons (Sonnentag et al., 2008), it is important to assess them as they occur rather than relying on onepoint-in-time retrospective assessments which do not capture day-to-day fluctuations and are prone to recall biases (Ohly, Sonnentag, Niessen, \& Zapf, 2010).

Second, change patterns in outcome variables can be monitored over the entire study period, providing insights into the processes involved in the intervention: For instance, change may occur linearly, such that the control group remains stable while the intervention group shows a linear increase in outcome variables. Yet, it is also possible that largest gains may be reaped in the beginning of the intervention and remain stable once a certain level is reached. Alternatively, a certain period of training may be necessary before the intervention has an effect on outcome variables such that intervention and control group remain similar in the beginning and then start to grow apart. These differences in the processes involved in an intervention are only detectable if outcome variables are repeatedly measured in small time intervals during the intervention. In this study, we therefore use event-sampling methodology, involving daily measurements of mindfulness, psychological detachment, sleep quality, and sleep duration, and analyse change trajectories in outcome variables over 10 workdays. 


\section{Method}

\section{Procedure}

Participants were randomly assigned to the self-training intervention or the wait-list control group. Both groups received a paper-and-pencil diary booklet consisting of the introductory survey and diary surveys for 10 workdays. Participants were asked to fill in the introductory survey before starting with the diary part.

For participants in the intervention group, the self-training intervention was integrated into the diary while participants in the control group received a booklet with the selftraining intervention after completion of the study.

\section{The self-training intervention}

We used the self-training intervention developed by Hülsheger et al. (2013) that builds upon key elements and exercises of Mindfulness-Based Cognitive Therapy (MBCT; Segal, Williams, \& Teasdale, 2002) and MBSR (Kabat-Zinn, 1982, 1990). First, participants received some general information about mindfulness and mindfulness meditation along with instructions when and how to perform the exercises. Similar to MBCT and MBSR, the self-training intervention consisted of daily guided mindfulness meditations and informal mindfulness exercises. Specifically, participants were sequentially familiarized with the following mindfulness practices: The Body Scan, the Three-minute Breathing Space, the Mindful Routine Activity exercise, and a Loving Kindness Meditation exercise. All of these exercises aim at cultivating an open-hearted attention towards externally and internally generated stimuli. As an essential part of mindfulness trainings, participants were encouraged to develop an open and compassionate mindset in performing all of these exercises. Table 1 provides brief descriptions of the exercises and an overview when each exercise was introduced and how often participants were asked to perform them. For each exercise, participants first received some brief written information as well as audio files with guided meditations. When performing mindfulness meditation exercises, participants typically realize how difficult it is to stay focused on the present moment and how easily one gets distracted by thoughts. This may cause frustration and make it even more difficult to stay focused on the present moment. Participants were therefore repeatedly encouraged to not criticize or blame themselves but to simply realize when they get distracted and to be kind and indulgent to themselves and their weaknesses.

\section{Participants}

The sample was a convenience sample recruited from a broad range of organizations in Germany. The majority of participants was approached directly and mostly in person. Some participants were contacted via mail first. Others received a flyer with an invitation to the study from colleagues or supervisors. Overall, 220 diary booklets were distributed, 148 of which were returned (75 intervention group, 73 control group), resulting in an overall response rate of $67.3 \%$. Notably, the actual response rate is likely to be lower because some supervisors forwarded information on the study and flyers to an unknown number of individuals and some individuals who were approached individually may not have accepted a diary booklet in the first place.

As a compliance check, participants in the intervention group were asked every day to indicate whether they had engaged in their daily mindfulness meditation exercises. A total of eight participants either indicated on all 10 days to not have engaged in the mindfulness 
Table I. Schedule and description of mindfulness exercises involved in the self-training intervention

\begin{tabular}{|c|c|c|c|c|c|c|c|c|}
\hline \multirow[b]{2}{*}{ Day } & \multirow{2}{*}{\multicolumn{2}{|c|}{$\begin{array}{l}\text { Three-minute } \\
\text { breathing } \\
\text { space }\end{array}$}} & \multirow[b]{2}{*}{$\begin{array}{l}\text { Body } \\
\text { scan }\end{array}$} & \multirow{2}{*}{$\begin{array}{l}\text { Mindful } \\
\text { routine } \\
\text { activity }\end{array}$} & \multicolumn{4}{|c|}{ Loving kindness } \\
\hline & & & & & $\mathrm{Me}$ & Friend & $\begin{array}{l}\text { Neutral } \\
\text { person }\end{array}$ & $\begin{array}{l}\text { Disliked } \\
\text { person }\end{array}$ \\
\hline \multirow[t]{2}{*}{ I } & Morning & & & & & & & \\
\hline & Evening & $x$ & $x$ & & & & & \\
\hline \multirow[t]{2}{*}{2} & Morning & $x$ & & $x$ & & & & \\
\hline & Evening & $x$ & & & & & & \\
\hline \multirow[t]{2}{*}{3} & Morning & $x$ & & $x$ & & & & \\
\hline & Evening & $x$ & & & $x$ & & & \\
\hline \multirow[t]{2}{*}{4} & Morning & $x$ & & $x$ & & & & \\
\hline & Evening & $x$ & & & $x$ & & & \\
\hline \multirow[t]{2}{*}{5} & Morning & $x$ & & $x$ & & & & \\
\hline & Evening & $x$ & & & & $x$ & & \\
\hline \multirow[t]{2}{*}{6} & Morning & $x$ & & $x$ & & & & \\
\hline & Evening & $x$ & & & & $x$ & & \\
\hline \multirow[t]{2}{*}{7} & Morning & $x$ & & $x$ & & & & \\
\hline & Evening & $x$ & & & & & $x$ & \\
\hline \multirow[t]{2}{*}{8} & Morning & $x$ & & $x$ & & & & \\
\hline & Evening & $x$ & & & & & & $x$ \\
\hline \multirow[t]{2}{*}{9} & Morning & $x$ & & $x$ & & & & \\
\hline & Evening & $x$ & & & & & & $x$ \\
\hline \multirow[t]{2}{*}{10} & Morning & $x$ & & $x$ & & & & \\
\hline & Evening & $x$ & $x$ & & & & & \\
\hline $\begin{array}{l}\text { Three-minute } \\
\text { Breathing } \\
\text { Space }\end{array}$ & \multicolumn{8}{|c|}{$\begin{array}{l}\text { Participants learn to strengthen the focus on the present moment. Central to this } \\
\text { exercise is the breath which functions as an anchor. Whenever distracting thoughts } \\
\text { appear, attention is gently brought back to the act of breathing. This exercise is } \\
\text { relatively short, and it can easily be implemented into individuals' (work-) life. It helps } \\
\text { to disrupt automatic behaviour and thinking patterns and to reconnect with the } \\
\text { present moment (Siegel, 20I0; Williams, Teasdale, Segal, \& Kabat-Zinn, 2007) }\end{array}$} \\
\hline Body Scan & \multicolumn{8}{|c|}{$\begin{array}{l}\text { Participants are instructed to bring attention and awareness to different body parts by } \\
\text { sequentially 'scanning' through them, starting with the feet and moving up from there } \\
\text { Doing so, participants pay attention to the physical sensations (pleasant and } \\
\text { unpleasant) that they recognize while focusing on the respective body part }\end{array}$} \\
\hline $\begin{array}{l}\text { The Mindful } \\
\text { Routine } \\
\text { Activity }\end{array}$ & \multicolumn{8}{|c|}{$\begin{array}{l}\text { Participants pick a routine activity (e.g., preparing breakfast, taking a shower) and try to } \\
\text { perform it in a mindful rather than automatic way by bringing full attention to it. } \\
\text { Whenever distracting thoughts cross the mind, attention is gently brought back to the } \\
\text { activity }\end{array}$} \\
\hline $\begin{array}{l}\text { Loving } \\
\text { Kindness }\end{array}$ & \multicolumn{8}{|c|}{$\begin{array}{l}\text { Goal of the Loving Kindness exercise is to cultivate love and kindness for others and } \\
\text { oneself (Shapiro \& Carlson, 2009). The exercise begins with focusing on the breath, } \\
\text { thereby bringing attention to the present moment. In the central part of the exercise, } \\
\text { participants send loving and compassionate feelings and wishes to themselves or } \\
\text { others and try to vividly picture these tender feelings. First, the Loving Kindness } \\
\text { Meditation focuses on the self, and it is then extended to others - First to individuals } \\
\text { with which one has a positive relationship, then to a neutral person, and finally to a } \\
\text { person with which one has a difficult relationship }\end{array}$} \\
\hline
\end{tabular}

Note. The Mindful Routine Activity exercise was introduced on the second evening, and participants were asked to perform it every day at a point in time that suited them best. 
meditation exercises or failed to answer the respective question on all 10 days of the study. These eight participants were dropped from analyses. The final sample therefore consisted of 140 participants (67, intervention group; 73, control group), 97 were female (69.3\%), one participant failed to indicate his/her gender. Participants held a variety of different jobs. A total of $15.7 \%$ were clerks (bank, accounting, insurance, payroll), $10.7 \%$ hairdressers, $8.6 \%$ merchants, $7.9 \%$ consultants, $6.4 \%$ kindergarten teachers and pedagogues, 5\% health care professionals (e.g., hearing aid acousticians, optometrists), $4.3 \%$ civil servants and police officers, $3.6 \%$ nurses, $2.9 \%$ were managers, HR professionals, physicians, and engineers respectively, $2.1 \%$ were secretaries or retail salespersons respectively, $1.4 \%$ were physiotherapists, athletic trainers or waiters respectively, the rest held other types of jobs or did not indicate their occupation. On average, they were 37 years of age $(S D=13.3)$ and had an organizational tenure of 11.2 years $(S D=11.5)$. Participants in the intervention and control group did not differ significantly regarding gender, tenure, and baseline levels of sleep quality and psychological detachment. Participants in the control group were significantly older $(M=39.96, p=.01$; Cohen's $d=-.45)$ compared to participants in the intervention group $(M=34.27)$. Furthermore, although not reaching statistical significance, baseline levels of mindfulness (control group $M=3.66$, intervention group $M=3.47, p=.12$; Cohen's $d=-.28$ ) and sleep duration (control group $M=6.59$, intervention group $M=6.23, p=.09$; Cohen's $d=-.31$ ) tended to differ somehow. On average, participants in the intervention group spent $10.5 \min (S D=7.0)$ on their daily mindfulness practices.

\section{Measures}

Data collection consisted of two parts: A general survey and the diary part including brief daily surveys that had to be answered three times a day (in the morning, at the end of work, before going to bed), for 10 workdays. All items were in German and had to be answered on 5-point Likert scales. The general questionnaire was completed before participants started filling in the diary part and before the intervention group received the mindfulness self-training intervention. In the general survey, demographic information and baseline measures were assessed:

\section{Trait mindfulness}

We assessed trait mindfulness with the German version (Michalak, Heidenreich, Ströhle, \& Nachtigall, 2008) of the 15-item Mindfulness Attention and Awareness Scale (MAAS; Brown \& Ryan, 2003). A (reversed) sample item is 'I find it difficult to stay focused on what's happening in the present'.

\section{Psychological detachment}

General psychological detachment after work was assessed with the respective 4-item scale of the Recovery Experience Questionnaire (Sonnentag \& Fritz, 2007). A sample item is 'I don't think about work at all'.

\section{Sleep quality and duration}

Participants' general levels of sleep quality and duration were assessed with the respective items from the Pittsburgh Sleep Quality Index (Buysse et al., 1989): 'On average, how do 
you evaluate your sleep?'; 'On average, how many hours of actual sleep do you get at night? (This may be different than the number of hours you spend in bed.)' These items have been used in studies on recovery from work stress (Hahn et al., 2011; Sonnentag et al., 2008).

In the diary part, sleep quality and duration were assessed in the morning survey, hours worked and mindfulness in the end of work survey, and psychological detachment in the bedtime survey.

\section{Sleep quality and duration}

Sleep quality and duration were assessed with the same items that were used in the general questionnaire, but participants were instructed to refer to the past night.

\section{Mindfulness}

Mindfulness during work was assessed with the German translation (Michalak et al., 2008) of the 5-item state version of the MAAS (Brown \& Ryan, 2003). Participants were instructed to refer to their experiences 'today during work' when answering the questions. A sample item is 'I rushed through activities without being really attentive to them'.

\section{Psychological detachment}

Psychological detachment was assessed with the same items used in the general questionnaire but referring to the respective evening.

\section{Control variables (work hours and age)}

In line with previous recovery research (Sonnentag et al., 2014), we controlled for work hours which have been shown to be associated with recovery-related outcomes such as fatigue and psychological detachment (Sanz-Vergel, Demerouti, Bakker, \& MorenoJimenez, 2011; Shirom, Nirel, \& Vinokur, 2009). At the end of work, participants reported the amount of hours they had worked: 'How many hours did you work today?'. Furthermore, we controlled for age, for which we had found significant baseline group differences (see sample description).

\section{Variance decomposition}

For variables that were assessed at the day level, we inspected the relative amount of within- and between-person variation by computing the ICC1 in an unconditional random coefficient model (Bliese, 2006). Results revealed ICC1 values between .23 and .54 (work hours: .54; mindfulness: .51; sleep quality: .23; sleep duration: .40; psychological detachment: .43), indicating that $46 \%$ of variance in work hours, $49 \%$ in mindfulness, $77 \%$ in sleep quality, $60 \%$ in sleep duration, and $57 \%$ in psychological detachment from work were lying within persons.

\section{Analyses}

Our data had a hierarchical structure with 10 daily reports nested in persons. To test the effects of the self-training intervention, we therefore used a random coefficient modelling 
framework that is suitable when one has multilevel data. This allowed us to conduct growth curve analyses and to fully exploit the longitudinal data structure by investigating change on dependent variables over time (i.e., over the 10-day period) and the extent to which these change trajectories were a function of condition (control vs. intervention group). For every dependent variable, we started out with testing how the dependent variable changed over time by modelling the fixed relationship between time (i.e., day of the study) and the dependent variable (Model 1) (Bliese \& Ployhart, 2002). Specifically, we modelled a linear relationship first and then progressed to model quadratic and cubic relationships (Bliese \& Ployhart, 2002). Once the form of the relationship between time and the dependent variable was established, we included a random slope parameter. We then tested for autoregressive structures (autocorrelation) and for systematic changes in the variance of responses over time (Bliese, 2006). Once error structures were properly specified and included in the model if necessary, we proceeded to test a cross-level interaction between time and condition (Model 2). Model 2 represents a conditional growth model and tests whether differences in change trajectories between participants (slope differences) can be explained by group membership (condition). Model 2 directly tests Hypothesis 1. A significant interaction term would indicate that changes in the dependent variable are a function of time and condition (e.g., values increase in one condition while remaining constant in the other condition). Hypothesis 2 was tested in Model 3 by including a three-way interaction with pre-intervention baseline levels. Hypothesis 2 would be supported if a significant three-way-interaction emerged and showed, for example, steeper increases in sleep quality in the intervention group for participants with low baseline levels compared to participants with high baseline levels.

\section{Results}

Intercorrelations between study variables, means, and $S D$ are depicted in Table 2.

We started our set of analyses with a manipulation check, by investigating changes in daily mindfulness. As can be seen from Table 3, Model 1 revealed that there was a significant positive linear relationship between time and mindfulness (there was no evidence for a quadratic or cubic relationship). In Model 2, a random slope parameter for time and a time-by-condition cross-level interaction were included. Results revealed a significant positive interaction between time and condition, showing that change patterns in mindfulness differed significantly between the control and the intervention group. A simple slope analysis was conducted to probe the interaction effect (Preacher, Curran, \& Bauer, 2006). There was no significant change in mindfulness for the control group (coef. $=-.01$, $p=.59)$, while there was a significant increase in mindfulness for the intervention group (coef. $=.03, p=.009$; see Figure 1). Taken together, these results confirm that the self-training intervention had a positive effect on daily mindfulness levels. Although not part of our hypotheses, we tested whether baseline levels of mindfulness interacted with time and condition in predicting daily mindfulness. Yet, as can be seen from Model 3, there was no evidence for a treatment-by-baseline interaction.

For psychological detachment from work, growth curve analyses revealed not only a significant linear relationship between time and psychological detachment, but also evidence for a significant quadratic and cubic relationship (Model 1). In Model 2, we therefore tested interaction effects between condition and linear, quadratic, and cubic 


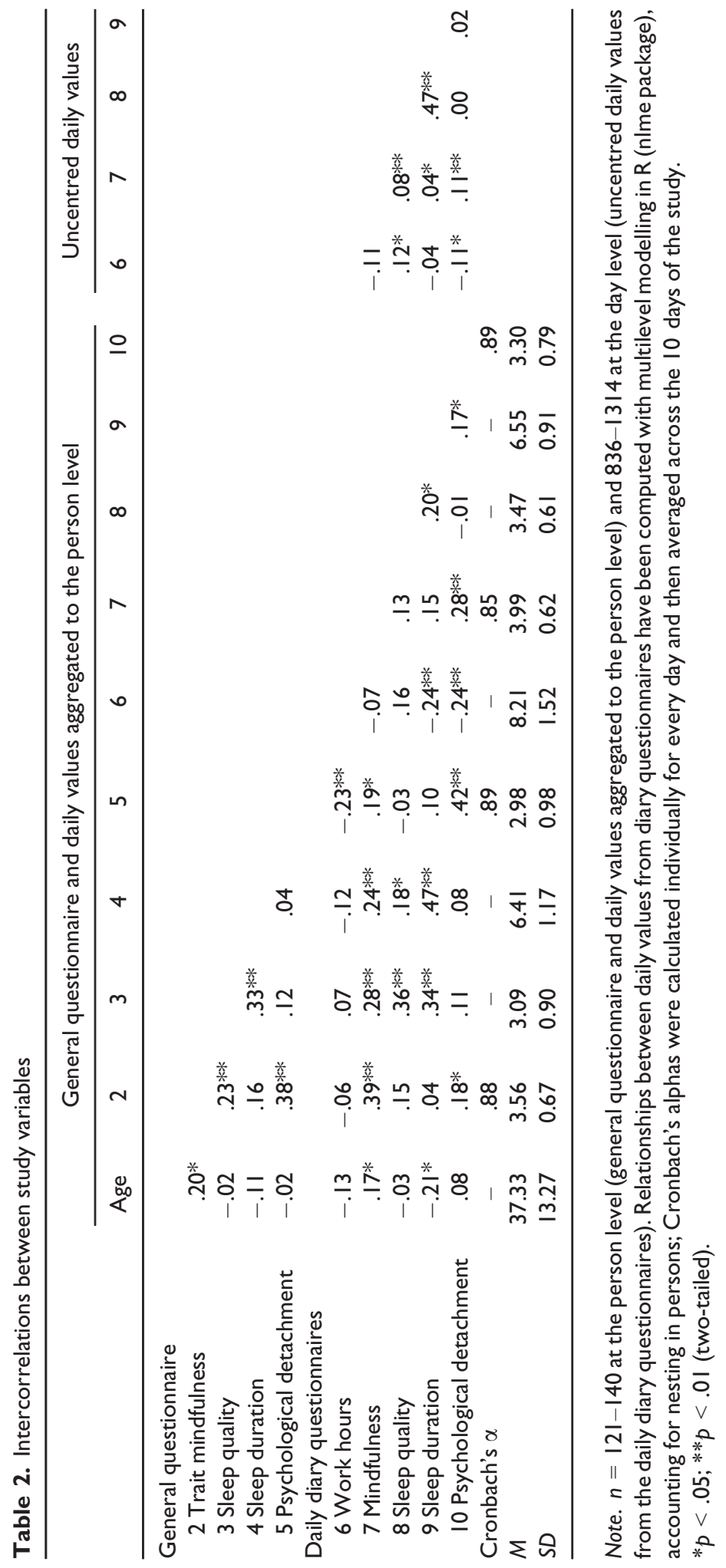


Table 3. Multilevel models predicting daily mindfulness and psychological detachment

\begin{tabular}{|c|c|c|c|c|c|c|}
\hline & \multicolumn{3}{|c|}{ Mindfulness } & \multicolumn{3}{|c|}{ Psychological detachment } \\
\hline & Model I & Model 2 & Model 3 & Model I & Model 2 & Model 3 \\
\hline \multicolumn{7}{|l|}{ Fixed effects } \\
\hline Intercept & $4.01 * *$ & $4.08^{* * *}$ & $4.07 * *$ & $3.17^{* *}$ & $3.07^{* *}$ & $3.07 * *$ \\
\hline Age & .06 & .05 & .05 & .07 & .08 & .08 \\
\hline Work hours & -.04 & -.04 & -.04 & $-.07 *$ & $-.07 *$ & $-.07 *$ \\
\hline Baseline & $.21 * *$ & $.24 * *$ & $.33^{*}$ & $.32 * *$ & $.33^{* *}$ & $.46 * *$ \\
\hline Condition & -.15 & $-.30 * *$ & $-.28^{*}$ & -.04 & .15 & .15 \\
\hline Time & $.01 *$ & -.01 & .00 & $.17^{*}$ & $.23 *$ & $.23^{*}$ \\
\hline Time $^{2}$ & & & & $-.05^{*}$ & $-.05^{*}$ & $-.05^{*}$ \\
\hline Time $^{3}$ & & & & $.003 *$ & .003 & .003 \\
\hline Time $\times$ Condition & & $.03 *$ & $.03^{\dagger}$ & & -.11 & -.11 \\
\hline Time $^{2} \times$ Condition & & & & & .01 & .01 \\
\hline Time $^{3} \times$ Condition & & & & & .00 & .00 \\
\hline Time $\times$ Condition $\times$ Baseline & & & -.01 & & & -.15 \\
\hline Time $^{2} \times$ Condition $\times$ Baseline & & & & & & .04 \\
\hline Time $^{3} \times$ Condition $\times$ Baseline & & & & & & .00 \\
\hline \multicolumn{7}{|l|}{ Random effects } \\
\hline Intercept & .285 & .255 & .252 & .405 & .421 & .408 \\
\hline Time & & .003 & .002 & & .011 & .011 \\
\hline Time $^{2}$ & & & & & .000 & .000 \\
\hline Time $^{3}$ & & & & & .000 & .000 \\
\hline Residual & .318 & .301 & .300 & .683 & .647 & .649 \\
\hline
\end{tabular}

Note. $N=125 \mid-1257$ observations nested in $135-137$ persons. Condition was coded as $0=$ control group and $\mathrm{I}=$ intervention group. Models 2 and 3 for mindfulness and psychological detachment allowed for autocorrelation because they fit the data significantly better than models assuming no autocorrelation. $* * p<.01 ; * p<.05 ; \dagger p=.05$ (two-tailed).

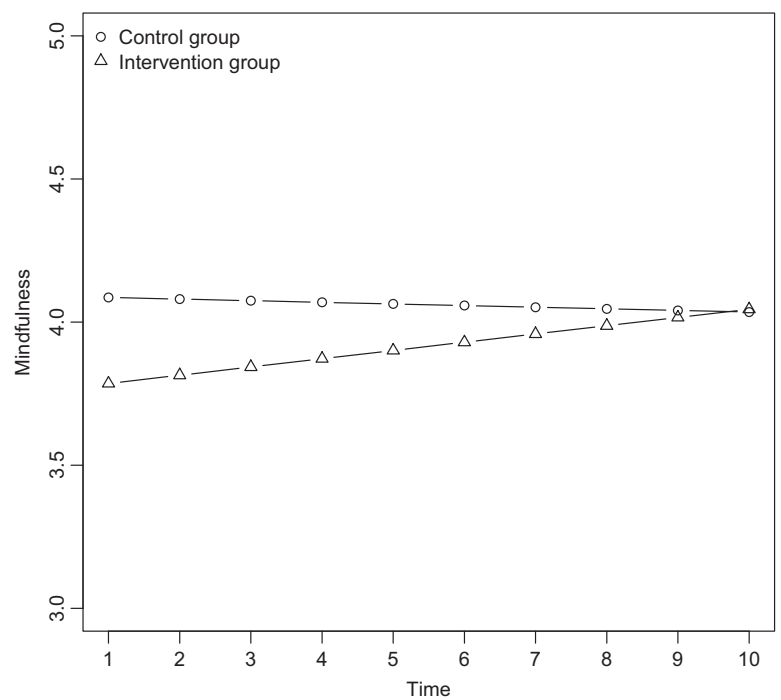

Figure I. Changes in daily mindfulness over time (day of the study) as a function of condition. 


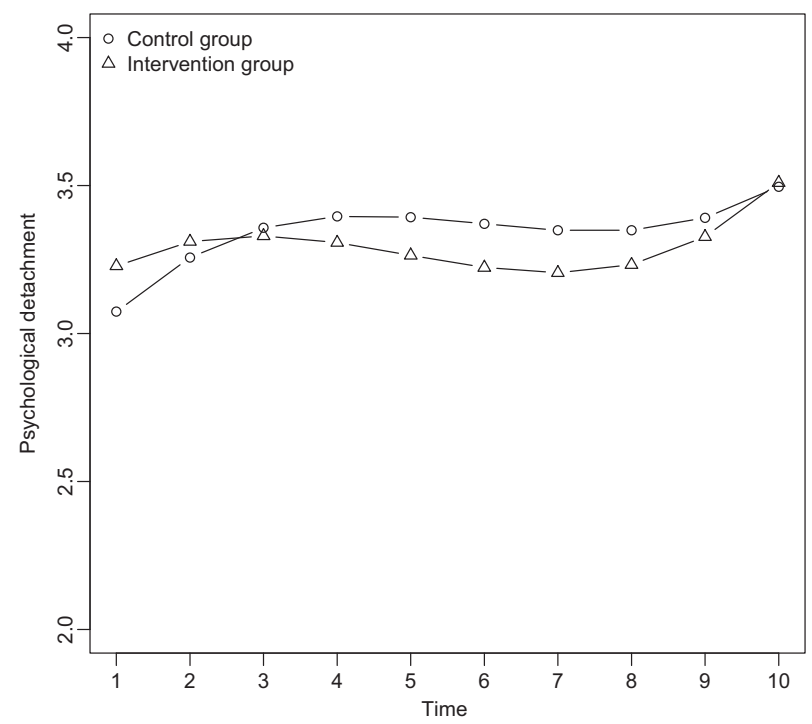

Figure 2. Changes in daily psychological detachment over time (day of the study) as a function of condition.

time trends, respectively. Yet, none of these interactions were significant, indicating that change patterns in psychological detachment were similar across conditions (see Figure 2 for a graphic illustration). Furthermore, there was no evidence for a treatment-by-baseline interaction (Model 3). Taken together, hypotheses 1a and 2a were therefore not supported.

For sleep quality, a significant positive fixed linear relationship between time and sleep quality emerged (Table 4, Model 1), while there was no evidence for quadratic or cubic time trends. Model 2 revealed a significant, positive cross-level interaction between condition and time, indicating that time-sleep quality slopes differed significantly between the control and the intervention group. Specifically, there was a decline in sleep quality in the control group (coef. $=-.03, p<.05$ ), while the intervention group experienced a significant increase in sleep quality over the 10-day period (coef. $=.10$, $p<.01$; see Figure 3). Hypothesis $1 \mathrm{~b}$ was thus supported. As can be seen from Model 3, there was no evidence for a treatment-by-baseline interaction in these change trajectories (Hypothesis 2b).

A similar pattern of results emerged for sleep duration: There was evidence for a significant positive linear relationship between time and sleep duration, while there was no evidence for quadratic or cubic trends (Model 1). Time-sleep duration slopes differed between conditions (Model 2); this difference reached a significance level of $p=.06$ when applying a conservative two-tailed test of significance. Researchers have argued that power to detect cross-level interaction effects in multilevel designs is typically low, especially when the sample size at Level 1 is relatively small (Mathieu, Aguinis, Culpepper, \& Chen, 2012; Snijders \& Bosker, 1999). Researchers have therefore suggested that a more lenient criterion of $p<.10$ may be applied for detecting cross-level interaction effects (Yeo \& Neal, 2004). A simple slope analysis showed that sleep duration did not change over time in the control group (estimate $=.01$, n.s.), while it significantly increased in the intervention group (estimate $=.05, p<.01$; see also Figure 4), supporting Hypothesis 
Table 4. Multilevel models predicting daily sleep quality and sleep duration

\begin{tabular}{|c|c|c|c|c|c|c|}
\hline & \multicolumn{3}{|c|}{ Sleep quality } & \multicolumn{3}{|c|}{ Sleep duration } \\
\hline & Model I & Model 2 & Model 3 & Model I & Model 2 & Model 3 \\
\hline \multicolumn{7}{|l|}{ Fixed effects } \\
\hline Intercept & $3.12 * *$ & $3.36 * *$ & 3.36 *** & $6.4 I^{* *}$ & $6.49 * *$ & $6.46 * *$ \\
\hline Age & .03 & .03 & .03 & $-.16^{*}$ & $-.16^{*}$ & $-.17^{*}$ \\
\hline Baseline & $.16 * *$ & $.19 * *$ & $.20 * *$ & $.4 I^{* *}$ & $.41^{* *}$ & $.56 * *$ \\
\hline Condition & $.42 *$ & -.10 & -.11 & .04 & -.11 & -.10 \\
\hline Time & $.03 * *$ & -.03 & -.03 & $.03 * *$ & .01 & .01 \\
\hline Time $\times$ Condition & & $.13^{* *}$ & $.13^{* *}$ & & $.04^{\dagger}$ & $.03^{\dagger}$ \\
\hline Time $\times$ Condition $\times$ Baseline & & & .00 & & & -.01 \\
\hline \multicolumn{7}{|l|}{ Random effects } \\
\hline Intercept & .133 & .045 & .048 & .439 & .439 & .429 \\
\hline Time & & .002 & .002 & & .000 & .000 \\
\hline Residual & .687 & .638 & .638 & .925 & .923 & .924 \\
\hline
\end{tabular}

Note. $N=926-1179$ observations nested in $122-135$ persons. Condition was coded as $0=$ control group and $\mathrm{I}=$ intervention group.

$* * p<.01 ; * p<.05 ; \dagger p<.10$ (two-tailed).

1c. Hypothesis 2c was not confirmed; the treatment-by-baseline interaction was not significant. $^{2}$

\section{Discussion}

Given the importance of recovery for the prevention of long-term health impairments (Geurts \& Sonnentag, 2006) on the one hand and the scarcity of recovery management interventions (Hahn et al., 2011) on the other hand, the present study set out to investigate the effectiveness of a low-dose mindfulness self-training intervention for psychological detachment, sleep quality, and sleep duration. Study findings were mixed, providing support for some but not all hypotheses: Results revealed that a brief selftraining mindfulness intervention was effective in increasing daily levels of mindfulness during work, sleep quality, and sleep duration over the course of 10 workdays. However, contrary to expectations, the intervention had no effect on psychological detachment in the evening. This finding is surprising, considering that earlier research suggests that mindfulness facilitates psychological detachment. For instance, Hülsheger et al. (2014) found that daily self-reported mindfulness during work was significantly related to psychological detachment in the evening. Furthermore, previous studies conducted outside the work context documented that traditional mindfulness-based interventions led to reduced levels of rumination (Jain et al., 2007; Manicavasagar, Perich, \& Parker, 2012; Shapiro et al., 2007), a construct that is inversely related to psychological detachment. Similarly, a recent study found a 3-week mindfulness-based intervention to

\footnotetext{
${ }^{2}$ In testing treatment-by-baseline interactions, we used trait measures of the respective outcome measures as a baseline. In the case of sleep quality and sleep duration, an alternative baseline measure may be sleep quality and sleep duration assessed in the morning of the first day of the study before the intervention started. The pattern of results was similar to results reported above: No significant treatment-by-baseline effect emerged for sleep quality (estimate $=.00$, n.s.) and for sleep duration (estimate $=.00$, n.s.).
} 


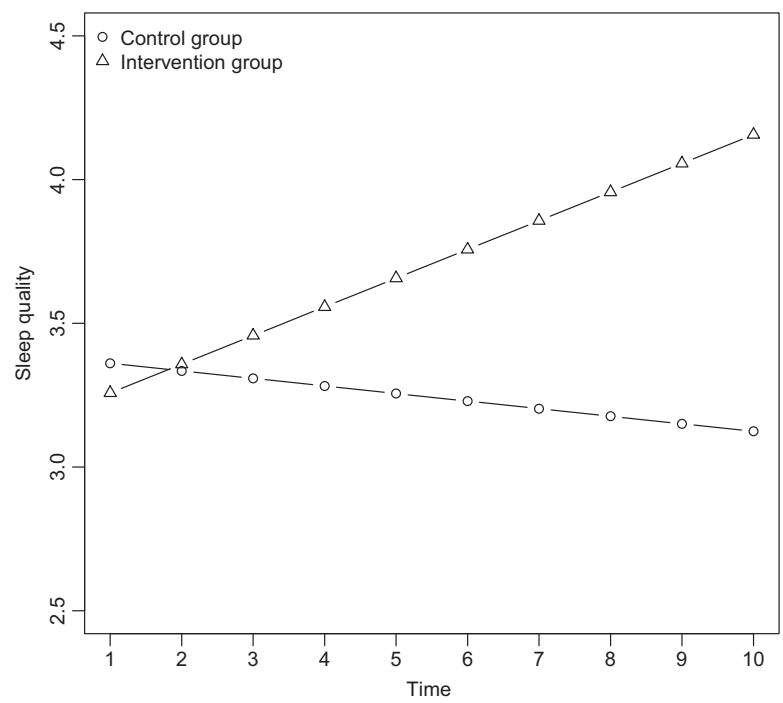

Figure 3. Changes in daily sleep quality over time (day of the study) as a function of condition.

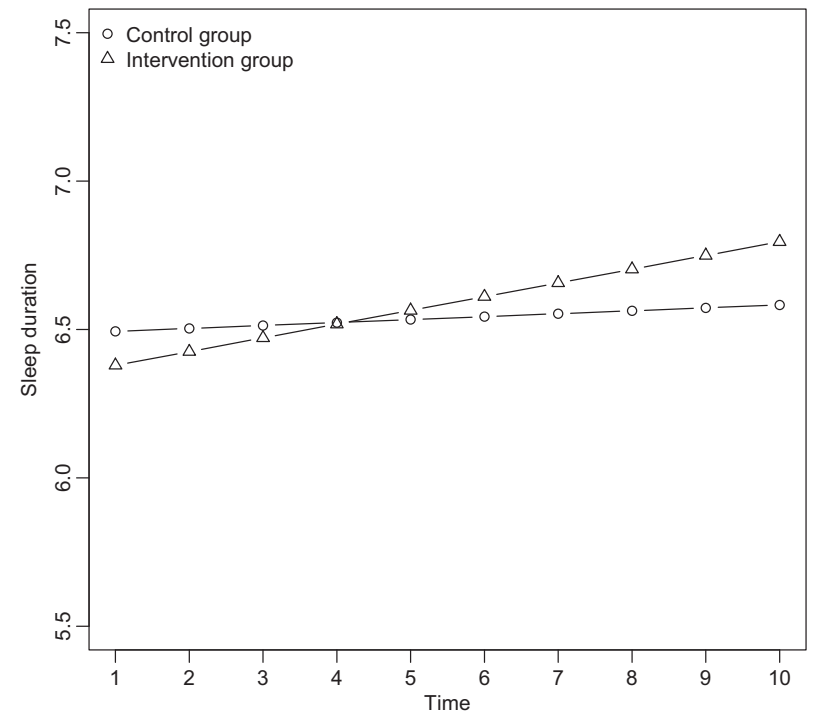

Figure 4. Changes in daily sleep duration (in hours) over time (day of the study) as a function of condition.

be effective in increasing psychological detachment in a sample of employees (Michel et al., 2014). Possibly, the present intervention, being of relatively short duration (2 weeks) and involving a comparatively small amount of daily practice time (on average $10.5 \mathrm{~min}$ as opposed to $45 \mathrm{~min}$ in traditional mindfulness interventions), may not have been intensive enough to yield effects on psychological detachment. In addition to mindfulness-specific elements, Michel et al.'s (2014) intervention contained a nonmindfulness-related module focusing on the importance of psychological detachment 
and the segmentation of work and private life which may have driven or strengthened the effects of the overall intervention on psychological detachment.

In addition to studying main effects of the intervention, we explored whether the intervention had differential effects for groups of participants. However, the data provided no evidence for treatment-by-baseline effects, neither for daily mindfulness nor for the three outcome variables. A potential explanation of the missing treatment-bybaseline interactions may lie in the specifics of the present sample. Typically, treatmentby-baseline interactions that have been documented in intervention and prevention research describe a scenario where an intervention has stronger effects on participants who are vulnerable, at risk, or display low psychological functioning before the intervention (Khoo, 2001; MacKinnon et al., 2007). The present sample was a nonclinical sample of employees. It is therefore likely that their overall level of psychological functioning may have been comparatively high and that none or very few participants may have been truly at risk in terms of clinical levels of rumination or insomnia, making it difficult to find the expected treatment-by-baseline interaction. Supplementary analyses provide some support for this view. On average, participants' initial levels of sleep quality, sleep duration, psychological detachment, and neuroticism were of medium size (preintervention sleep quality: $M=3.09, S D .90$; first-day sleep quality: $M=3.35, S D=.93$ : pre-intervention sleep duration: $M=6.41, S D$ 1.17; first-day sleep duration: $M=6.43$, $S D=1.21$; pre-intervention psychological detachment: $M=2.98, S D=.98$; first-day psychological detachment: $M=3.1, S D=1.12$; pre-intervention neuroticism: $M=2.85$, $S D=.73$ ), suggesting that participants had regular levels of psychological functioning.

Overall, our findings provide additional evidence that mindfulness-based interventions may be a useful supplement to workplace health promotion programmes (Cohen-Katz et al., 2005; Galantino et al., 2005; Wolever et al., 2012). Specifically, our findings show that even a low-dose self-training intervention that only spans two workweeks in contrast to 8 weeks and that only involves written information and audio files instead of weekly group meetings with a mindfulness trainer has the potential to benefit employee health and well-being by promoting daily recovery processes.

Importantly, our study provided additional insights into the processes involved in the present self-training intervention by evaluating it with event-sampling methodology. Typical evaluation studies compare pre-intervention measures to post-intervention and follow-up measures and inform on the overall effectiveness of the intervention. In contrast, evaluating the intervention with daily assessments shed light on what happens between pre- and post-intervention measurements and how effects of the intervention unfold over time. Growth curve analyses revealed that as of the first days of the intervention, gains in mindfulness, sleep quality, and sleep duration appeared. This is not surprising when one considers that even brief 10- to 15-min mindful-breathing exercises have been shown to have immediate positive effects on emotion regulation and positive and negative affect in laboratory experiments (Arch \& Craske, 2006; Erisman \& Roemer, 2010; Hafenbrack, Kinias, \& Barsade, 2014). Furthermore, our analyses showed that these gains gradually increased in a linear fashion over the 10-day period indicating that the benefits of mindfulness practice build up as participants practice and gain experience with it.

\section{Limitations and future directions}

Despite these strengths, the present study had limitations and these suggest several possibilities for future research. Although it is an interesting finding in itself that even 
after 10 days of mindfulness training, effects emerged, important additional insights could be gained from extending the training period to four or more weeks: It would allow investigating whether effects on psychological detachment develop after a longer period of training. Furthermore, it is likely that training effects on sleep quality and duration stop increasing in a linear fashion after some time of practice and reach a plateau at a certain point. Future research may also include follow-up measurements. These would provide important insights into whether and for how long participants continue practicing independently and how long training effects persist after the formal training phase is over.

Another limitation of the present study is the wait-list control group design which is common for initial tests of psychological interventions but has certain limitations as it may create expectation biases or experimenter demand (Fredrickson, Cohn, Coffey, Pek, \& Finkel, 2008; Hülsheger et al., 2013). Future research will also benefit from comparing the self-training mindfulness intervention to other interventions, including traditional mindfulness interventions, traditional organizational stress management interventions, or a recovery training programme (Hahn et al., 2011).

As reported in the method section, the control and the intervention group tended to differ regarding baseline levels of mindfulness and sleep duration, although these differences were not statistically significant. Regarding mindfulness, the relative difference in starting values is apparent from Figure 1, which shows that participants in the intervention group started with lower levels of mindfulness on day 1 than participants in the control group. Notably, we controlled for baseline levels in outcome variables to account for these differences. Furthermore, our analyses focus on differences in changes in outcome variables between intervention and control group over the 10-day study period rather than on absolute differences in outcome variables between intervention and control group.

Finally, we did not focus on the effect of our intervention on specific processes involved in recovery from work, such as psychological detachment from negative work experiences by promoting a non-evaluative attitude towards those events. A way to extend knowledge on these processes involved in the effectiveness of mindfulness interventions is to consider daily negative events at work and test whether individuals receiving a mindfulness intervention react more adaptively to negative work events as we suggested in the introduction.

In conclusion, this study advanced both the recovery literature and the mindfulness literature by providing evidence that a brief self-training intervention is effective in improving participants' daily levels of mindfulness during work, their sleep quality, and sleep duration.

\section{Acknowledgement}

We wish to thank Annika in der Beek and Sissy Büscher for their help in collecting data.

\section{References}

Allen, T. D., \& Kiburz, K. M. (2012). Trait mindfulness and work-family balance among working parents: The mediating effects of vitality and sleep quality. Journal of Vocational Behavior, 80 , 372-379. doi:10.1016/j.jvb.2011.09.002 
Arch, J. J., \& Craske, M. G. (2006). Mechanisms of mindfulness: Emotion regulation following a focused breathing induction. Behavior Research and Therapy, 44, 1849-1858. doi:10.1016/j.brat.2005.12.007

Baer, R. A. (2003). Mindfulness training as a clinical intervention: A conceptual and empirical review. Clinical Psychology: Science and Practice, 10, 125-143. doi:10.1093/clipsy/bpg015

Barclay, N. L., Eley, T. C., Buysse, D. J., Tijsdijk, F. V., \& Gregory, A. M. (2010). Genetic and environmental influences on different components of the Pittsburgh Sleep Quality Index and their overlap. Sleep, 33, 659-668.

Barnes, C. M., Ghumman, S., \& Scott, B. A. (2013). Sleep and organizational citizenship behavior: The mediating role of job satisfaction. Journal of Occupational Health Psychology, 18, 16-26. doi:10.1037/a0030349

Barnes, C. M., Wagner, D. T., \& Ghumman, S. (2012). Borrowing from sleep to pay work and family: Expanding time-based conflict to the broader nonwork domain. Personnel Psychology, 65, 789-819. doi:10.1111/peps.12002

Binnewies, C., Sonnentag, S., \& Mojza, E. J. (2009). Daily performance at work: Feeling recovered in the morning as a predictor of day-level job performance. Journal of Organizational Behavior, 30, 67-93. doi:10.1002/job.541

Bishop, S. R., Lau, M., Shapiro, S., Carlson, L., Anderson, N. D., Carmody, J. . . Devins, G. (2004). Mindfulness: A proposed operational definition. Clinical Psychology: Science and Practice, 11, 230-241. doi:10.1093/clipsy.bph077

Bliese, P. D. (2006). Multilevel modeling in R (2.2): A brief introduction to $R$, the multilevel package and the nlme package. Washington, DC: Walter Reed Army Institute of Research.

Bliese, P. D., \& Ployhart, R. E. (2002). Growth modeling using random coefficient models: Model building, testing, and illustrations. Organizational Research Methods, 5, 362-387. doi: $10.1177 / 109442802237116$

Bond, F. W., Flaxman, P. E., \& Bunce, D. (2008). The influence of psychological flexibility on work redesign: Mediated moderation of a work reorganization intervention. Journal of Applied Psychology, 93, 645-654. doi:10.1037/0021-9010.93.3.645

Broomfield, N. M. \& Espie, C.A. (2003). Initial insomnia and paradoxical intention: An experimental investigation of putative mechanisms using subjective and actigraphic measurement of sleep. Behavioural and Cognitive Psychotherapy, 31, 313-324. doi:10.1017/\$1352465803003060

Brown, K. W., \& Ryan, R. M. (2003). The benefits of being present: Mindfulness and its role in psychological well-being. Journal of Personality and Social Psychology, 84, 822-848. doi:10.1037/0022-3514.84.4.822

Brown, K. W., Ryan, R. M., \& Creswell, J. D. (2007). Mindfulness: Theoretical foundations and evidence for its salutary effects. Psychological Inquiry, 18, 211-237. doi:10.1080/ 10478400701598298

Buysse, D. J., Reynolds, C. F., Monk, T. H., Berman, S. R., \& Kupfer, D. J. (1989). Pittsburgh Sleep Quality Index (PSQI). Psychiatry Research, 28, 193-213. doi:10.1016/0165-1781(89)90047-4

Cameron, O. G. (2001). Interoception : The inside story - A model for psychosomatic processes. Psychosomatic Medicine, 710, 697-710. doi:10.1097/00006842-200109000-00001.

Cohen-Katz, J., Wiley, S., Capuano, T., Baker, D. M., Deitrick, L., \& Shapiro, S. (2005). The effects of mindfulness-based stress reduction on nurse stress and burnout: A qualitative and quantitative study, part III. Holistic Nursing Practice, 19, 26-35. doi:10.1097/00004650-200501000-00008

Cook, T. D., \& Campbell, D. T. (1979). Quasi-experimentation: Design and analysis issues for field settings. Boston, MA: Houghton Mifflin.

Craig, A. (2003). Interoception: The sense of the physiological condition of the body. Current Opinion in Neurobiology, 13, 500-505. doi:10.1016/S0959-4388(03)00090-4

Dane, E., \& Brummel, B. J. (2014). Examining workplace mindfulness and its relations to job performance and turnover intention. Human Relations, 67, 105-128. doi:10.1177/ 0018726713487753 
Demsky, C. A., Ellis, A. M., \& Fritz, C. (2014). Shrugging it off: Does psychological detachment from work mediate the relationship between workplace aggression and work-family conflict? Journal of Occupational Health Psychology, 19, 195-205. doi:10.1037/a0035448

Dreyfus, G. (2011). Is mindfulness present-centred and non-judgmental? A discussion of the cognitive dimensions of mindfulness. Contemporary Buddhism, 12, 41-54. doi:10.1080/ 14639947.2011 .564815

Eden, D., \& Aviram, A. (1993). Self-Efficacy training to speed reemployment : Helping people to help themselves. Journal of Applied Psychology, 78, 352-360. doi:10.1037/0021-9010.78.3.352

Eden, D., \& Kinnar, J. (1991). Modeling Galatea: Boosting self-efficacy to increase volunteering. Journal of Applied Psychology, 76, 770-780. doi:10.1037/0021-9010.76.6.770

Emmons, R. A., \& McCullough, M. E. (2003). Counting blessings versus burdens: An experimental investigation of gratitude and subjective well-being in daily life. Journal of Personality and Social Psychology, 84, 377-389. doi:10.1037/0022-3514.84.2.377

Erisman, S. M., \& Roemer, L. (2010). A preliminary investigation of the effects of experimentally induced mindfulness on emotional responding to film clips. Emotion, 10, 72-82. doi:10.1037/ a0017162

Etzion, D., Eden, D., \& Lapidot, Y. (1998). Relief from job stressors and burnout: Reserve service as a respite. Journal of Applied Psychology, 83, 577-585. doi:10.1037/0021-9010.83.4.577

Fredrickson, B. L., Cohn, M. A., Coffey, K. A., Pek, J., \& Finkel, S. M. (2008). Open hearts build lives: Positive emotions, induced through loving-kindness meditation, build consequential personal resources. Journal of Personality and Social Psychology, 95, 1045-1062. doi:10.1037/ a0013262

Fritz, C., \& Sonnentag, S. (2009). Antecedents of day-level proactive behavior: A look at job stressors and positive affect during the workday. Journal of Management, 35, 94-111. doi:10.1177/0149206307308911

Fritz, C., Yankelevich, M., Zarubin, A., \& Barger, P. (2010). Happy, healthy, and productive: The role of detachment from work during nonwork time. Journal of Applied Psychology, 95, 977-983. doi: $10.1037 / \mathrm{a} 0019462$

Füstös, J., Gramann, K., Herbert, B. M., \& Pollatos, O. (2013). On the embodiment of emotion regulation: Interoceptive awareness facilitates reappraisal. Social Cognitive and Affective Neuroscience, 8, 472-477. doi:10.1093/scan/nss089

Galantino, M. L., Baime, M., Maguire, M., Szapary, P. O., \& Farrar, J. T. (2005). Association of psychological and physiological measures of stress in health-care professionals during an 8-week mindfulness meditation program: Mindfulness in practice. Stress and Health, 21, 255-261. doi: $10.1002 / \mathrm{smi} .1062$

Geurts, S. A., \& Sonnentag, S. (2006). Recovery as an explanatory mechanism in the relation between acute stress reactions and chronic health impairment. Scandinavian Journal of Work, Environment \& Health, 32, 482-492. doi:10.5271/sjweh.1053

Glomb, T. M., Duffy, M. K., Bono, J. E., \& Yang, T. (2011). Mindfulness at work. In J. Martocchio, H. Liao \& A. Joshi (Eds.), Research in personnel and buman resource management (pp. 115-157). Bingley, UK: Emerald. doi:10.1108/S0742-7301(2011)0000030005

Hafenbrack, A. C., Kinias, Z., \& Barsade, S. G. (2014). Debiasing the mind through meditation: Mindfulness and the sunk-cost bias. Psychological Science, 25, 369-376. doi:10.1177/ 0956797613503853

Hahn, V. C., Binnewies, C., Sonnentag, S., \& Mojza, E. J. (2011). Learning how to recover from job stress: Effects of a recovery training program on recovery, recovery-related self-efficacy, and well-being. Journal of Occupational Health Psychology, 16, 202-216. doi:10.1037/a0022169

Hofmann, S. G., Sawyer, A. T., Witt, A. A., \& Oh, D. (2010). The effect of mindfulness-based therapy on anxiety and depression: A meta-analytic review. Journal of Consulting and Clinical Psychology, 78, 169-183. doi:10.1037/a0018555

Hölzel, B. K., Ott, U., Gard, T., Hempel, H., Weygandt, M., Morgen, K., \& Vaitl, D. (2008). Investigation of mindfulness meditation practitioners with voxel-based morphometry. Social Cognitive and Affective Neuroscience, 3, 55-61. doi:10.1093/scan/nsm038 
Hülsheger, U. R., Alberts, H. J. E. M., Feinholdt, A., \& Lang, J. W. B. (2013). Benefits of mindfulness at work: The role of mindfulness in emotion regulation, emotional exhaustion, and job satisfaction. Journal of Applied Psychology, 98, 310-325. doi:10.1037/a0031313

Hülsheger, U. R., Lang, J. W. B., Depenbrock, F., Fehrmann, C., Zijlstra, F. R. H., \& Alberts, J. E. M. (2014). The power of presence: The role of mindfulness at work for daily levels and change trajectories of psychological detachment and sleep quality. Journal of Applied Psychology, 99, 1113-1128.

Irving, J. A., Dobkin, P. L., \& Park, J. (2009). Cultivating mindfulness in health care professionals: A review of empirical studies of mindfulness-based stress reduction (MBSR). Complementary Therapies in Clinical Practice, 15, 61-66. doi:10.1016/j.ctcp.2009.01.002

Jacobs, T. L., Epel, E. S., Lin, J., Blackburn, E. H., Wolkowitz, O. M., Bridwell, D. A., ... Saron, C. D. (2011). Intensive meditation training, immune cell telomerase activity, and psychological mediators. Psychoneuroendocrinology, 36, 664-681. doi:10.1016/j.psyneuen.2010.09.010

Jain, S., Shapiro, S. L., Swanick, S., Roesch, S. C., Mills, P. J., Bell, I., \& Schwartz, G. E. R. (2007). A randomized controlled trial of mindfulness meditation versus relaxation training: Effects on distress, positive states of mind, rumination, and distraction. Annals of Behavioral Medicine, 1 , 11-21. doi:10.1207/s15324796abm3301_2

Kabat-Zinn, J. (1982). An outpatient program in behavioral medicine for chronic pain patients based on the practice of mindfulness meditation: Theoretical considerations and preliminary results. General Hospital Psychiatry, 4, 33-47. doi:10.1016/0163-8343(82)90026-3

Kabat-Zinn, J. (1990). Full catastrophe living: Using the wisdom of your mind to face stress, pain and illness. New York, NY: Dell.

Kabat-Zinn, J. (2003). Mindfulness-based interventions in context : Past-, present-, and future. Clinical Psychology: Science and Practice, 10, 144-156. doi:10.1093/clipsy.bpg016

Kerr, C. E., Sacchet, M. D., Lazar, S. W., Moore, C. I., \& Jones, S. R. (2013). Mindfulness starts with the body: Somatosensory attention and top-down modulation of cortical alpha rhythms in mindfulness meditation. Frontiers in Human Neuroscience, 7, 1-15. doi:10.3389/fnhum.2013.00012

Khoo, S. T. (2001). Assessing program effects in the presence of treatment-baseline interactions: A latent curve approach. Psychological Methods, 6, 234-257. doi:10.1037/ 1082-989X.6.3.234

Klatt, M. D., Buckworth, J., \& Malarkey, W. B. (2009). Effects of low-dose mindfulness-based stress reduction (MBSR-ld) on working adults. Health Education \& Behavior, 36, 601-614. doi: $10.1177 / 1090198108317627$

Krasner, M. S., Epstein, R. M., Beckman, H., Suchman, A. L., Chapman, B., Mooney, C. J., \& Quill, T. E. (2009). Association of an educational program in mindful communication with burnout, empathy, and attitudes among primary care physicians. JAMA, 203, 1284-1293. doi:10.1001/ jama.2009.1384

Kristeller, J., Wolever, R. Q., \& Sheets, V. (2013). Mindfulness-Based Eating Awareness Training (MB-EAT) for binge eating: A randomized clinical trial. Mindfulness, 5, 282-297. doi:10.1007/ s12671-012-0179-1

Luthans, F., Avey, J. B., \& Patera, J. L. (2008). Experimental analysis of a web-based training intervention to develop positive psychological capital. Academy of Management Learning $\&$ Education, 7, 209-221.

Lyubomirsky, S., \& Layous, K. (2013). How do simple positive activities increase well-being? Current Directions in Psychological Science, 22, 57-62. doi:10.1177/0963721412469809

Lyubomirsky, S., Sheldon, K. M., \& Schkade, D. (2005). Pursuing happiness: The architecture of sustainable change. Review of General Psychology, 9, 111-131. doi:10.1037/10892680.9.2.111

MacKinnon, D. P., Fairchild, A. J., \& Fritz, M. S. (2007). Mediation analysis. Annual Review of Psychology, 58, 593-614. doi:10.1146/annurev.psych.58.110405.085542

Malarkey, W. B., Jarjoura, D., \& Klatt, M. (2013). Workplace based mindfulness practice and inflammation: A randomized trial. Brain, Behavior, and Immunity, 27, 145-154. doi:10.1016/ j.bbi.2012.10.009 
Manicavasagar, V., Perich, T., \& Parker, G. (2012). Cognitive predictors of change in cognitive behaviour therapy and mindfulness-based cognitive therapy for depression. Behavioural and Cognitive Psychotherapy, 40, 227-232. doi:10.1017/\$1352465811000634

Marzuq, N., \& Drach-Zahavy, A. (2012). Recovery during a short period of respite: The interactive roles of mindfulness and respite experiences. Work \& Stress, 26, 175-194. doi:10.1080/ 02678373.2012 .683574

Mathieu, J. E., Aguinis, H., Culpepper, S. A., \& Chen, G. (2012). Understanding and estimating the power to detect cross-level interaction effects in multilevel modeling. Journal of Applied Psychology, 97, 951-966. doi:10.1037/a0028380

Meijman, T. F., \& Mulder, G. (1998). Psychological aspects of workload. In P. J. D. Drenth \& H. Thierry (Eds.), Handbook of work and organizational psychology: Work psychology (pp. 5-33). Hove, UK: Psychology Press.

Meyers, M. C., van Woerkom, M., \& Bakker, A. B. (2013). The added value of the positive: A literature review of positive psychology interventions in organizations. European Journal of Work and Organizational Psychology, 22, 618-632. doi:10.1080/1359432X.2012.694689

Michalak, J., Heidenreich, T., Ströhle, G., \& Nachtigall, C. (2008). Die deutsche Version der Mindful Attention and Awareness Scale (MAAS): Psychometrische Befunde zu einem Achtsamkeitsfragebogen [German Version of the Mindful Attention and Awareness Scale (MAAS): Psychometric properties of a mindfulness inventory]. Zeitschrift fuer Klinische Psychologie und Psychotherapie, 37, 200-208. doi:10.1026/1616-3443.37.3.200

Michel, A., Bosch, C., \& Rexroth, M. (2014). Mindfulness as a cognitive - emotional segmentation strategy: An intervention promoting work - life balance. Journal of Occupational and Organizational Psychology, 87, 733-754. doi:10.1111/joop.12072

Ohly, S., Sonnentag, S., Niessen, C., \& Zapf, D. (2010). Diary studies in organizational research: An introduction and some practical recommendations. Journal of Personnel Psychology, 9, 79-93. doi:10.1027/1866-5888/a000009

Ong, J. C., Cardé, N. B., Gross, J. J., \& Manber, R. (2011). A two-dimensional approach to assessing affective states in good and poor sleepers. Journal of Seep Research, 20, 606-610. doi:10.1111/ j.1365-2869.2011.00907.x

Ong, J. C., Shapiro, S. L., \& Manber, R. (2008). Combining mindfulness meditation with cognitivebehavior therapy for insomnia: A treatment-development study. Behavior Therapy, 39, 171182. doi:10.1016/j.beth.2007.07.002

Ouweneel, E., Le Blanc, P. M., \& Schaufeli, W. B. (2013). Do-it-yourself: An online positive psychology intervention to promote positive emotions, self-efficacy, and engagement at work. Career Development International, 18, 173-196. doi:10.1108/CDI-10-2012-0102

Pereira, D., \& Elfering, A. (2014). Social stressors at work and sleep during weekends: The mediating role of psychological detachment. Journal of Occupational Health Psychology, 19(1), 85-95. doi: $10.1037 / \mathrm{a} 0034928$

Pereira, D., Meier, L. L., \& Elfering, A. (2013). Short-term effects of social exclusion at work and worries on sleep. Stress and Health, 29, 240-252. doi:10.1002/smi.2461

Preacher, K. J., Curran, P. J., \& Bauer, D. J. (2006). Computational tools for probing interactions in multiple linear regression, multilevel modeling, and latent curve analysis. Journal of Educational and Behavioral Statistics, 31, 437-448. doi:10.3102/10769986031004437

Querstret, D., \& Cropley, M. (2012). Exploring the relationship between work-related rumination, sleep quality, and work-related fatigue. Journal of Occupational Health Psychology, 17, 341353. doi:10.1037/a0028552

Reb, J., Narayanan, J., \& Ho, Z. W. (2015). Mindfulness at work: Antecedents and consequences of employee awareness and absent-mindedness. Mindfulness, 6, 111-122. doi:10.1007/s12671013-0236-4

Rosenzweig, S., Greeson, J. M., Reibel, D. K., Green, J. S., Jasser, S. A., \& Beasley, D. (2010). Mindfulness-based stress reduction for chronic pain conditions: Variation in treatment outcomes and role of home meditation practice. Journal of Psychosomatic Research, 68, 2936. doi:10.1016/j.jpsychores.2009.03.010 
Roth, A., \& Fonagy, P. (2005). What works for whom: A critical review of psychotherapy research (2nd ed.). New York, NY: Guilford.

Sanz-Vergel, A. I., Demerouti, E., Bakker, A. B., \& Moreno-Jimenez, B. (2011). Daily detachment from work and home: The moderating effect of role salience. Human Relations, 64, 775-799. doi:10.1177/0018726710393368

Schmidt, A. F., Eulenbruch, T., Langer, C., \& Banger, M. (2013). Interoceptive awareness, tension reduction expectancies and self-reported drinking behavior. Alcohol and Alcoholism, 48, 472477. doi:10.1093/alcalc/agt024

Sears, S. R., Kraus, S., Carlough, K., \& Treat, E. (2011). Perceived benefits and doubts of participants in a weekly meditation study. Mindfulness, 2, 167-174. doi:10.1007/s12671-011-0055-4

Segal, Z., Williams, M. R., \& Teasdale, J. (2002). Mindfulness-based cognitive therapy for depression: A new approach to preventing relapse. New York, NY: Guilford Press.

Shapiro, S. L., Brown, K. W., \& Biegel, G. M. (2007). Teaching self-care to caregivers: Effects of mindfulness-based stress reduction on the mental health of therapists in training. Training and Education in Professional Psychology, 1, 105-115. doi:10.1037/1931-3918.1.2.105

Shapiro, S. L., Brown, K. W., Thoresen, C., \& Plante, T. G. (2011). The moderation of mindfulnessbased stress reduction effects by trait mindfulness: Results from a randomized controlled trial. Journal of Clinical Psychology, 67, 267-277. doi:10.1002/jclp.20761

Shapiro, S. L., \& Carlson, L. E. (2009). The art and science of mindfulness: Integrating mindfulness into psychology and the helping professions. Washington, DC: American Psychological Association.

Shapiro, S. L., Carlson, L. E., Astin, J. A., \& Freedman, B. (2006). Mechanisms of mindfulness. Journal of Clinical Psychology, 62, 373-386. doi:10.1002/jclp.20237

Shirom, A., Nirel, N., \& Vinokur, A. D. (2009). Work hours and caseload as predictors of physician burnout: The mediating effects by perceived workload and by autonomy. Applied Psychology: An International Review, 59, 539-565. doi:10.1111/j.1464-0597.2009.00411.x

Siegel, R. D. (2010). The mindful solution: Everyday practices for everyday problems. New York, NY: Guilford Press.

Snijders, T., \& Bosker, R. (1999). Multilevel analysis: An introduction to basic and advanced multilevel modeling. London, UK: Sage.

Sonnentag, S. (2001). Work, recovery activities, and individual well-being: A diary study. Journal of Occupational Health Psychology, 6, 196-210. doi:10.1037/1076-8998.6.3.196

Sonnentag, S., Arbeus, H., Mahn, C., \& Fritz, C. (2014). Exhaustion and lack of psychological detachment from work during off-job time: Moderator effects of time pressure and leisure experiences. Journal of Occupational Health Psychology, 19, 206-216. doi:10.1037/a0035760

Sonnentag, S., Binnewies, C., \& Mojza, E. J. (2008). Did you have a nice evening? A day-level study on recovery experiences, sleep, and affect. Journal of Applied Psychlogy, 93, 674-684. doi:10.1037/0021-9010.93.3.674

Sonnentag, S., Binnewies, C., \& Mojza, E. J. (2010). Staying well and engaged when demands are high: The role of psychological detachment. Journal of Applied Psychology, 95, 965-976. doi:10.1037/a0020032

Sonnentag, S., \& Fritz, C. (2007). The recovery experience questionnaire: Development and validation of a measure. Journal of Occupational Health Psychology, 12, 204-221.

Sonnentag, S., \& Fritz, C. (2015). Recovery from job stress: The stressor-detachment model as an integrative framework. Journal of Organizational Behavior, 36, S72-S103. doi:10.1002/ job. 1924

Sonnentag, S., Mojza, E. J., Demerouti, E., \& Bakker, A. B. (2012). Reciprocal relations between recovery and work engagement: The moderating role of job stressors. Journal of Applied Psychology, 97, 842-853. doi:10.1037/a0028292

Sonnentag, S., \& Zijlstra, F. R. H. (2006). Job characteristics and off-job activities as predictors of need for recovery, well-being, and fatigue. Journal of Applied Psychology, 91, 330-350. doi:10.1037/0021-9010.91.2.330 
Van 't Wout, M., Faught, S., \& Menino, D. (2013). Does interoceptive awareness affect the ability to regulate unfair treatment by others? Frontiers in Psychology, 4, 472-477. doi:10.3389/ fpsyg.2013.00880

Van Berkel, J., Boot, C. R. L., Proper, K. I., Bongers, P. M., \& van der Beek, A. J. (2013). Process evaluation of a workplace health promotion intervention aimed at improving work engagement and energy balance. Journal of Occupational and Environmental Medicine, 55, 19-26. doi:10.1097/JOM.0b013e318269e5a6

Williams, J. M. G. (2010). Mindfulness and psychological process. Emotion, 10, 1-7. doi:10.1037/ a0018360

Williams, M., Teasdale, J., Segal, Z., \& Kabat-Zinn, J. (2007). The mindful way through depression: Freeing yourself from chronic unhappiness. New York, NY: The Guilford Press.

Wolever, R. Q., Bobinet, K. J., McCabe, K., Mackenzie, E. R., Fekete, E., Kusnick, C. A., \& Baime, M. (2012). Effective and viable mind-body stress reduction in the workplace: A randomized controlled trial. Journal of Occupational Health Psychology, 17, 246-258. doi:10.1037/ a0027278

Wolitzky-Taylor, K. B., Arch, J. J., Rosenfield, D., \& Craske, M. G. (2012). Moderators and nonspecific predictors of treatment outcome for anxiety disorders: A comparison of cognitive behavioral therapy to acceptance and commitment therapy.Journal of Consulting and Clinical Psychology, 80, 786-799. doi:10.1037/a0029418

Yeo, G. B., \& Neal, A. (2004). A multilevel analysis of effort, practice, and performance: Effects of ability, conscientiousness, and goal orientation. Journal of Applied Psychology, 89, 231-247. doi:10.1037/0021-9010.89.2.231

Received I June 20I4; revised version received 23 February 2015 